Heimberg, M., Park, J. H., Isaacs, A. \& Pitt-Rivers, R. (1955). Endocrinology, 57, 756.

Larson, F. C. \& Albright, E. C. (1958). Endocrinology, 68, 183.

Lerman, J. \& Pitt-Rivers, R. (1955). J. clin. Endocrin. 15, 653.

Maclagan, N. F. \& Reid, D. (1957). Ciba Foundation Colloq. Endocrin. 10, 190.

Maclagan, N.F.\& Sheahan, M.M. (1950). J.Endocrin. 6, 456.

Maclagan, N. F., Sprott, W. E. \& Wilkinson, J. H. (1952). Lancet, ii, 915.

Pitt-Rivers, R. (1953). Lancet, ii, 234.

Roche, J., Michel, R., Closon, J. \& Michel, O. (1957). C.R. Soc. Biol., Paris, 151, 1101.

Roche, J., Michel, R., Jouan, P. \& Wolf, W. (1955). C.R. Acad. Sci., Paris, 241, 1880.
Roche, J., Michel, R., Jouan, P. \& Wolf, W. (1956a). C.R. Soc. Biol., Paris, 150, 461.

Roche, J., Michel, R., Jouan, P. \& Wolf, W. (1956b). Endocrinology, 59, 425.

Sheahan, M. M., Wilkinson, J. H. \& Maclagan, N. F. (1951). Biochem. J. 48, 188.

Thibault, O. \& Pitt-Rivers, R. (1955). Lancet, i, 285.

Trotter, W. R. (1955). Lancet, ii, 374.

Wilkinson, J. H. (1956). Biochem. J. 63, 601.

Wilkinson, J. H. (1958). Biochem. J. 68, 1 P.

Wilkinson, J. H. \& Feetham, A. J. (1955). Biochem. J. 59, 21.

Wilkinson, J. H. \& Maclagan, N. F. (1954). Biochem. J. 58, 87.

Wilkinson, J. H., Sprott, W. E., Bowden, C. H. \& Maclagan, N. F. (1954). Biochem. J. 56, 215.

\title{
A Method for the Estimation of Dehydroepiandrosterone in Urine
}

\author{
BY K. FOTHERBY \\ Clinical Endocrinology Research Unit (Medical Research Council), University of Edinburgh
}

(Received 9 March 1959)

The evidence indicating the origin of dehydroepiandrosterone (3 $\beta$-hydroxyandrost-5-en-17-one) in the adrenal cortex (cf. Lieberman, 1956) has been strengthened by the isolation of this steroid from an adrenal tumour by Plantin, Diczfalusy \& Birke (1957). The work of Landau, Knowlton, Lugibihl \& Munson (1951), Bitman \& Cohen (1951), Dingemanse, Huis in't Veld \& Hartogh-Katz (1952) and Ronzoni (1952) suggested that dehydroepiandrosterone was one of the major 17-oxo steroids in urine. Accordingly its estimation in urine should provide a method of measuring one aspect of adrenal function.

Many methods for the estimation of dehydroepiandrosterone or of the $\beta$-fraction of urine extracts, of which dehydroepiandrosterone was thought to be the only steroid component, have been described. The earlier methods in which dehydroepiandrosterone was purified via the digitonide and estimated by the Zimmermann reaction (Talbot, Butler, MacLachlan \& Jones, 1940; Baumann \& Metzger, 1940; Frame, 1944; Salter, Cahen \& Sappington, 1946; Dobriner, 1953) or polarographically (Butt, Henly \& Morris, 1948), or methods in which dehydroepiandrosterone after purification by means of the Girard separation is estimated by the Allen, Hayward \& Pinto (1950) reaction (Ronzoni, 1952) or the Pettenkofer reaction (Munson, Jones, McCall \& Gallagher, 1948; Landau et al. 1951 ; Bray \& Merivale, 1953; Prunty, 1953), or the methods of Talbot, Ryan \& Wolfe (1943), Bitman \& Cohen $(1949,1951)$ and Jensen \& Totterman (1952), in which dehydroepiandro- sterone is liberated from its conjugate by heating under neutral or slightly acid conditions, lack specificity since no chromatographic separation is used. Fotherby (1958) showed that substances other than dehydroepiandrosterone, which give positive Pettenkofer and Zimmermann reactions and are precipitated with digitonin, occur in the ketonic fractions of urine extracts. Moreover, most of the earlier methods employ acid hydrolysis at elevated temperatures, which results in the production of artifacts and thus may not be quantitative. In few cases has the sensitivity of the method or the accuracy based upon the amount of added steroid recovered been adequately determined. These remarks also apply to the method described by Cohen \& Oneson (1953), in which the steroid sulphates are hydrolysed with dioxan and trichloroacetic acid. Fotherby (unpublished work) found that while pure potassium dehydroepiandrosterone sulphate is readily hydrolysed by this method the recovery of steroid when the conjugate is added to urine or to urine extracts is poor, presumably owing to the presence of inhibitors of the reaction in the urine extract.

Recently methods for the determination of the major 17-oxo steroids, including dehydroepiandrosterone, present in urine have been developed, in which either column chromatography (Dingemanse et al. 1952; Kellie \& Wade, 1957) or paper chromatography (Brooks, 1958; Bush, 1959) is employed, but these methods are lengthy.

It therefore seemed desirable to have a method for the estimation of dehydroepiandrosterone in 
urine that was simple and reliable; the development of such a method, which is described in the present paper, has been made possible by using a procedure for the hydrolysis of the sulphates of the $3 \beta$-hydroxy- $\Delta^{5}$-steroids which appears to be specific for these conjugates.

Talbot et al. (1943) and Bitman \& Cohen (1949, $1951)$ showed that the sulphates of $3 \beta$-hydroxy- $\Delta^{5}$. steroids were labile in that they were readily hydrolysed. Thus sodium dehydroepiandrosterone sulphate could be hydrolysed by heating a solution in acetate buffer (pH 5.8 or 4.7 ) for $4 \mathrm{hr}$. at $100^{\circ}$, whereas the sulphates of the saturated 3-hydroxy steroids were not hydrolysed. Teich, Rogers, Lieberman, Engel \& Davis (1953) investigated the hydrolysis of sodium dehydroepiandrosterone sulphate and showed that the products of the hydrolysis depended on the $\mathrm{pH}$ of the solution. When a solution of dehydroepiandrosterone sulphate in a buffer of pH 6.8 was heated under a layer of toluene the major product of the hydrolysis was $6 \beta$. hydroxy-3:5-cycloandrostan-17-one, accompanied by a small amount of dehydroepiandrosterone.

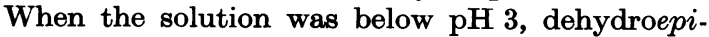
androsterone, but no 6 $\beta$-hydroxy-3:5-cycloandrostan-17-one, was isolated, and under these conditions $3 \beta$-chloroandrost-5-en-17-one and androsta3:5-dien-17-one may also be produced. More recently Roy (1956) has shown that, although the sulphates of a number of $3 \beta$-hydroxy- $\Delta^{5}$-steroids are hydrolysed by heating solutions of these compounds at $\mathrm{pH} 7$ at $100^{\circ}$, the sulphates of other steroids are not affected. Thus heating the sulphates of $3 \beta$-hydroxy- $\Delta^{\mathbf{5}}$-steroids in approximately neutral solution appears to be a specific method for the hydrolysis of these conjugates.

\section{EXPERIMENTAL}

Materials. Ethanol (absolute) was refluxed with KOH pellets and twice distilled. Benzene (A.R.) was redistilled. Acetic acid and sulphuric acid were of A.R. quality. Furfuraldehyde was twice distilled, used immediately to prepare a $0.56 \%(\mathrm{v} / \mathrm{v})$ soln. in $50 \%(\mathrm{v} / \mathrm{v})$ aqueous acetic acid, and stored in the refrigerator. Alumina (Hopkin and Williams Ltd., M.F.C., purified, neutral, Brockmann activity =1) was deactivated by adding water $(4 \mathrm{ml} . / 100 \mathrm{~g}$.), stirring to break down moist lumps and shaking for 4-6 hr. The activity was checked by its behaviour with pure dehydroepiandrosterone. Potassium dehydroepiandrosterone sulphate was prepared as described by Roy (1956) (Found: C, $56 \cdot 4$; H, 6.6; K, 9.7. Calc.: C, 56.1 ; H, 6.7; K, 9.6\%).

Method for the estimation of dehydroepiandrosterone. For urine from normal humans a $20 \mathrm{ml}$. sample of a $24 \mathrm{hr}$. collection was used. The urine was pipetted into a tube with a ground-glass socket and heated without adjustment of the $\mathrm{pH}$ under a condenser in a boiling-water bath for $6 \mathrm{hr}$. (A smaller volume of urine should be used and diluted to $20 \mathrm{ml}$. with water if the dehydroepiandrosterone content is expected to be high.) After cooling the urine was extracted with $40 \mathrm{ml}$. of benzene and the benzene extract washed once with $20 \mathrm{ml}$. of water. A portion (35 ml.) of the benzene extract was measured into a boiling tube (6 in. $x$ 1 in.) and evaporated to a small volume (about $5 \mathrm{ml}$.) at $40-60^{\circ}$ under a stream of air.

The benzene was then transferred by means of a capillary pipette to a column $(6 \mathrm{~cm} . \times \mathbf{0 . 5} \mathrm{cm}$.) of alumina prepared in benzene. The tube which had contained the benzene extract was rinsed with a further $2 \mathrm{ml}$. of benzene and this was also added to the column. When the benzene had almost passed through the column a further $8 \mathrm{ml}$. of benzene was added to the column and the benzene eluates were discarded. The dehydroepiandrosterone and $6 \beta$ hydroxy-3:5-cycloandrostan-17-one were then eluted from the column with $30 \mathrm{ml}$. of $0 \cdot 1 \%(\mathrm{v} / \mathrm{v})$ ethanol in benzene. This eluate was evaporated to dryness in a warm-water bath under a stream of air, and the residue, together with the standards (20 and $40 \mu \mathrm{g}$. of dehydroepiandrosterone) and a reagent blank, was subjected to the modified Pettenkofer reaction (Munson et al. 1948; Fotherby, 1958). The extinctions of the solutions were read at 620,660 and $700 \mathrm{~m} \mu$ and the corrected extinction at $660 \mathrm{~m} \mu$ calculated by using Allen's (1950) correction formula.

\section{RESULTS}

Hydrolysis of potassium dehydroepiandrosterone sulphate. A study of the rate of hydrolysis of potassium dehydroepiandrosterone sulphate in aqueous solution at $\mathrm{pH} 7$ at $100^{\circ}$ has shown that the reaction proceeds rapidly at first, approximately $60 \%$ of the conjugate being hydrolysed during the first $2 \mathrm{hr}$., and thereafter decreases in velocity, being approximately $80 \%$ complete after $5 \mathrm{hr}$. and $90 \%$ complete after $6 \mathrm{hr}$. Amounts of potassium dehydroepiandrosterone sulphate, varying from 5 to $50 \mu \mathrm{g}$. in $20 \mathrm{ml}$. of solution, were used in these experiments, the liberated steroids being extracted with benzene and estimated by the modified Pettenkofer reaction and by the Zimmermann reaction (Callow, Callow \& Emmens, 1938).

For the routine procedure a hydrolysis period of $6 \mathrm{hr}$. was adopted since the hydrolysis is almost complete after this time. The hydrolysis of the dehydroepiandrosterone sulphate in urine also appears to be complete within $6 \mathrm{hr}$., for if urine which has been hydrolysed for $6 \mathrm{hr}$. and extracted is reheated for a further period of $6 \mathrm{hr}$. and again extracted no dehydroepiandrosterone is detectable in this second extract.

The evidence at present available (Kellie \& Smith, 1957) shows that most, if not all, of the dehydroepiandrosterone detected in urine is present as the $3 \beta$-sulphate, so that heating urine without adjustment of the $\mathrm{pH}$ should quantitatively hydrolyse the conjugate of dehydroepiandrosterone and also the conjugates of the other $3 \beta$-hydroxy$\Delta^{5}$-steroids present in urine, but should not hydrolyse conjugates of other steroids. Extracts of urine hydrolysed in the above manner are thus less 
contaminated with non-steroid material or with other steroids than are extracts of urine hydrolysed by other methods.

It has been shown by paper chromatography with the solvent system light petroleum-methanolwater (5:4:1, by vol.) that approximately equal amounts of dehydroepiandrosterone and $6 \beta$ hydroxy-3:5-cycloandrostan-17-one are present in the extracts of urine hydrolysed without acidification. None of the artifact $3 \beta$-chloroandrost-5-en17-one which was isolated by Bitman \& Cohen (1951) from extracts of urine hydrolysed by their method was detected; nor could one expect it to be present, since the $\mathrm{pH}$ of the urine usually increases by 1-2 units during the hydrolysis, so that acidic conditions which favour the formation of this artifact are not obtained. Also, when potassium dehydroepiandrosterone sulphate in $20 \%(\mathrm{w} / \mathrm{v})$ sodium chloride solution or sodium hydroxide solution ( $\mathrm{pH} \mathrm{10)}$ is hydrolysed by boiling these solutions and the extract is chromatographed on alumina, the amount of material in the dehydroepiandrosterone fraction reacting positively in the Pettenkofer reaction is equal to that found when an equivalent amount of potassium dehydroepiandrosterone sulphate is hydrolysed in aqueous solution at $\mathrm{pH}$ 7. The rate and extent of hydrolysis of dehydroepiandrosterone sulphate is not decreased by the presence of sulphate ions in the solution.

Separation and estimation of dehydroepiandro-

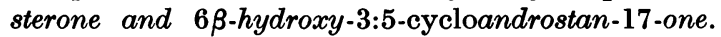
The dehydroepiandrosterone and 6 $\beta$-hydroxy-3:5cycloandrostan-17-one liberated by the hydrolysis of urine can be purified by chromatography on a column $(6 \mathrm{~cm} . \times 0.5 \mathrm{~cm}$.) of alumina. After passing $15 \mathrm{ml}$. of benzene through the column to remove substances which are present in some urines and interfere in the subsequent colour reaction the dehydroepiandrosterone and 6 $\beta$-hydroxy-3:5-cycloandrostan-17-one are eluted together by $30 \mathrm{ml}$. of $0.1 \%(\mathrm{v} / \mathrm{v})$ ethanol in benzene. Androst-5-ene3 $\beta$ :17 $\beta$-diol, which has also been shown to occur in the urine of normal humans (Fotherby, 1958) and of patients with an adrenal tumour (Schiller, Miller, Dorfman, Sevringhaus \& McCullagh, 1945; Hirschmann \& Hirschmann, 1945; Mason \& Kepler, 1945), is not eluted by $50 \mathrm{ml}$. of $0 \cdot 1 \%(\mathrm{v} / \mathrm{v})$ ethanol in benzene.

Variation in the conditions for the Pettenkofer reaction. The effect of varying the conditions under which the reaction is performed has been investigated. As the concentration of the furfuraldehyde was increased the extinction produced from equimolar amounts of dehydroepiandrosterone was found to increase, but so also did the extinction of the reagent blank. Increasing the molarity of the sulphuric acid used increased the extinction of the reagent blank, and when the molarity of the acid was decreased a much longer time was needed for colour development. A longer time for development was also required when the temperature at which the reaction was performed was decreased. Thus the intensity of colour produced by the incubation of dehydroepiandrosterone at $45^{\circ}$ for $1 \mathrm{hr}$. was similar to that produced by a $12 \mathrm{~min}$. incubation period at $70^{\circ}$, with $8 \mathrm{M}$-sulphuric acid and $0.56 \%(v / v)$ furfuraldehyde solution. The latter conditions, which are the ones described by Munson et al. (1948), have been used in the present method. Under these conditions the reagent blank has very little colour (extinction less than 0.020 at $660 \mathrm{~m} \mu$ ), and because of the short reaction time a large number of estimations can be performed rapidly.

As the length of the incubation period at $70^{\circ}$ was increased the extinction at $660 \mathrm{~m} \mu$ of both the standard solution and the reagent blank increased, whereas the corrected extinction at $660 \mathrm{~m} \mu$ decreased; after incubation for $1 \mathrm{hr}$. the corrected extinction had fallen by one-third of the value obtained after a $12 \mathrm{~min}$. incubation period. The colour developed by incubation for $12 \mathrm{~min}$. is stable at room temperature for at least $2 \mathrm{hr}$.

There is a slight day-to-day variation in the intensity of the colour produced by the standard solution. Although the extinctions of solutions are linearly related to the amount of dehydroepiandrosterone present, the slope of the line obtained with amounts of dehydroepiandrosterone greater than $20 \mu \mathrm{g}$. is less steep than the slope obtained with amounts of dehydroepiandrosterone between 0 and $20 \mu \mathrm{g}$. For this reason it is advisable to include two standard amounts (20 and $40 \mu \mathrm{g}$.) of dehydroepiandrosterone with each series of estimations. The intensity of colour produced by equal amounts of dehydroepiandrosterone and 6 $\beta$-hydroxy-3:5-cycloandrostan-17-one is identical. Presumably under the acidic conditions of the Pettenkofer reaction the 6 $\beta$-hydroxy-3:5-cyclosteroid is converted into the $3 \beta$-hydroxy $-\Delta^{5}$-steroid, since this transformation is known to occur in dilute acid solution.

Evaluation of the method. The values found for the excretion of dehydroepiandrosterone by 28 normal men (ages 18-63 years) range from 0.2 to $4.5 \mathrm{mg}$./ day (mean $1.2 \mathrm{mg}$.), and for 28 normal females (ages 18-72 years) the range is $0.0-2.0 \mathrm{mg} . /$ day (mean $0.5 \mathrm{mg}$.). These amounts constitute 4-30\% and $3-28 \%$ respectively of the total 17-oxo steroids. Five patients who have been treated with amounts of adrenocorticotrophic hormone sufficient to produce maximal stimulation of the adrenal have shown increases in dehydroepiandrosterone excretion varying from three- to twenty-fold compared with the pre-stimulation values.

The recovery of dehydroepiandrosterone from water or urine to which potassium dehydroepiandrosterone sulphate has been added is shown in 
Table 1. The results shown in Table 1 also give an indication of the sensitivity of the method. The recovery of dehydroepiandrosterone after the addition of potassium dehydroepiandrosterone sulphate to water or to urine from adrenalectomized humans is good. The recovery from the urine of normal humans, while acceptable, is a little lower, presumably because of the difficulty in measuring the dehydroepiandrosterone from the added conjugate in the presence of that originally present in the urine.

By using the formula described by Snedecor (1952) an estimate of the precision of the method can be calculated from the difference between the two results of duplicate determinations in a series of estimations. From duplicate estimations of dehydroepiandrosterone on forty-five different urine samples the estimate of the precision expressed as the estimate of the standard deviations of the results from the means of the duplicate estimations is 0.06 (calculated in terms of $\mathrm{mg} . /$ $24 \mathrm{hr}$.).

\section{DISCUSSION}

On the evidence available (Lieberman, 1956) dehydroepiandrosterone appears to originate solely in the adrenal cortex, so that the estimation of this steroid in urine provides a method of measuring one aspect of adrenocortical function. It should be emphasized, however, that the function of dehydroepiandrosterone and the pathway by which it is produced are at present unknown. This steroid seems nevertheless to be of some importance, for it appears to be the major 17-oxo steroid present in blood (Migeon, 1955; Kellie \& Smith, 1957).

The range of values obtained by the method described for the amount of dehydroepiandro-

\section{Table 1. Recovery of dehydroepiandrosterone from water and urine}

In column 3 the results are expressed as \pm s.D., with the numbers of estimations in parentheses.

\begin{tabular}{|c|c|}
\hline $\begin{array}{l}\text { Wt. of potassium } \\
\text { dehydroepi- } \\
\text { androsterone } \\
\text { sulphate added } \\
\text { to } 20 \mathrm{ml} \text {. of fluid } \\
\text { ( } \mu \mathrm{g} .)\end{array}$ & $\begin{array}{c}\text { Mean percentage } \\
\text { recovery of } \\
\text { dehydroepi- } \\
\text { androsterone }\end{array}$ \\
\hline $\begin{array}{r}4 \cdot 8 \\
9 \cdot 6 \\
19 \cdot 2 \\
38 \cdot 4\end{array}$ & $\begin{array}{l}94 \pm 5(7) \\
81 \pm 3 \cdot 4(7) \\
89 \pm 9 \cdot 0(11) \\
96 \pm 3 \cdot 2(5)\end{array}$ \\
\hline $\begin{array}{r}4 \cdot 8 \\
9 \cdot 6 \\
19 \cdot 2 \\
38 \cdot 4\end{array}$ & $\begin{array}{l}97 \pm 11(7) \\
96 \pm 5 \cdot 5(7) \\
95 \pm 6(6) \\
94 \pm 4(6)\end{array}$ \\
\hline $\begin{array}{r}9 \cdot 6 \\
19 \cdot 2 \\
38 \cdot 4\end{array}$ & $\begin{array}{l}80 \pm 8(11) \\
79 \pm 8(15) \\
87 \pm 10(12)\end{array}$ \\
\hline
\end{tabular}

sterone excreted by normal males and females are similar to those reported by Kellie \& Wade (1957) and Brooks (1958), who have used methods, which appear to be reliable for the fractionation of urinary 17-oxo steroids, employing the Zimmermann reaction after column or paper chromatography. Thus Kellie \& Wade (1957) give values of $0.2-2.5 \mathrm{mg} . /$ day and $0.8-2.1 \mathrm{mg}$./day for six males and six females respectively, while Brooks (1958) found a range of $0 \cdot 1-1 \cdot 1 \mathrm{mg}$./day for six females.

Table 1 shows that the recovery of dehydroepiandrosterone after adding potassium dehydroepiandrosterone to water or to urine is good. These recovery figures are a measure of the accuracy of the method, since the dehydroepiandrosterone added to the urine is in the conjugated form in which it is known to occur in urine. The results shown in Table 1, particularly the recoveries from urine from adrenalectomized humans, indicate also the sensitivity of the method. Thus it is possible to measure accurately $3 \cdot 4 \mu \mathrm{g}$. of dehydroepiandrosterone added to $20 \mathrm{ml}$. of urine from adrenalectomized humans, and assuming a daily urine volume of $1500 \mathrm{ml}$. these values would correspond to an excretion of $0.25 \mathrm{mg}$. of dehydroepiandrosterone/day. The sensitivity could be increased by using a larger volume of urine for hydrolysis and extraction or by decreasing the volume of reagents used in the modified Pettenkofer reaction and using micro-cells for the measurement of the extinction.

The results obtained by performing duplicate determinations on a large number of samples of urine show that the reproducibility of the method is good, the estimate of the standard deviation of the results from their means being $0.06 \mathrm{mg} . / 24 \mathrm{hr}$.

The specificity of the method depends upon the specificity of the hydrolysis procedure, the chromatographic separation of the hydrolysis products and their estimation by the modified Pettenkofer reaction. Munson et al. (1948) have shown that this reaction is fairly specific for the $3 \beta$-hydroxy$\Delta^{5}$-steroids; although the chromogenic character of the members of this group of steroids varies widely, dehydroepiandrosterone produces one of the most intense colours - a factor which not only aids the sensitivity of the method but also minimizes the interference from other possible compounds that might be expected to be present, e.g. pregnenolone or pregn-5-ene-3 $\beta-20 \alpha$-diol, but which have not yet been demonstrated to occur in urine from normal humans. The method is simple and by its use dehydroepiandrosterone can be estimated rapidly and accurately.

Owing to the scarcity of a suitable enzyme preparation for the hydrolysis of steroid sulphates in urine, the method commonly used for hydrolysing these conjugates (Lieberman \& Dobriner, 1948; Kellie \& Wade, 1957; Brooks, 1958) con- 
sists in continuously extracting urine acidified to pH 1 for 48-72 hr. with ether. Recently Burstein \& Lieberman (1958) have described a solvolysis procedure for splitting these conjugates. Although these procedures hydrolyse the sulphates of the 3-hydroxy $-5 \alpha$ - and $-5 \beta$-steroids in addition to the $3 \beta$-hydroxy- $\Delta^{5}$-steroids, the former method has the disadvantage that the hydrolysis is slow and, more important, that more labile steroids, e.g. $3 \beta: 16 \alpha$-dihydroxyandrost-5-en-17-one, are destroyed by these conditions. Whether or not these labile steroids are destroyed by the method of Burstein \& Lieberman remains to be determined. The hydrolysis procedure used in the present method is comparatively quick and the more labile steroids appear not to be destroyed, so that the method should be capable of extension to include the other $3 \beta$-hydroxy- $\Delta^{5}$-steroids that have been shown to occur in the urine of normal males (Fotherby, 1958, 1959).

\section{SUMMARY}

1. A method for the estimation of dehydroepiandrosterone in urine is described in which the sulphate of this steroid is hydrolysed by heating urine without acidification at $100^{\circ}$ for $6 \mathrm{hr}$.

2. The criteria of reliability of the method are discussed.

I wish to thank Professor G. F. Marrian, F.R.S., for his interest in the work and Miss $\mathbf{N}$. Balloch and Miss $A$. Fleming for technical assistance.

\section{REFERENCES}

Allen, W. M. (1950). J. clin. Endocrin. Metab. 10, 71. Allen, W. M., Hayward, S. J. \& Pinto, A. (1950). J. clin. Endocrin. Metab. 10, 54.

Baumann, E. J. \& Metzger, N. (1940). Endocrinology, 27, 665.

Bitman, J. \& Cohen, S. L. (1949). J. biol. Chem. 179, 455. Bitman, J. \& Cohen, S. L. (1951). J. biol. Chem. 191, 351. Bray, B. M. \& Merivale, W. H. H. (1953). J. Endocrin. 9, 1. Brooks, R. V. (1958). Biochem. J. 68, 50.

Burstein, S. \& Lieberman, S. (1958). J. biol. Chem. 233, 331.
Bush, I. E. (1959). J. Endocrin. 18, 1.

Butt, W. R., Henly, A. A. \& Morris, C. J. O. R. (1948). Biochem. J. 42, 447.

Callow, N. H., Callow, R. K. \& Emmens, C. W. (1938). Biochem. J. 32, 1312.

Cohen, S. L. \& Oneson, I. B. (1953). J. biol. Chem. 204, 245.

Dingemanse, E., Huis in't Veld, L. G. \& Hartogh-Katz, S. L. (1952). J. clin. Endocrin. Metab. 12, 66.

Dobriner, K. (1953). J. clin. Invest. 32, 940.

Fotherby, K. (1958). Biochem. J. 69, 596.

Fotherby, K. (1959). Biochem. J. 71, 209.

Frame, E. G. (1944). Endocrinology, 34, 175.

Hirschmann, H. \& Hirschmann, F. B. (1945). J. biol. Chem. $157,601$.

Jensen, C. C. \& Totterman, L. E. (1952). Acta endocr., Copenhagen, 11, 33.

Kellie, A. E. \& Smith, E. R. (1957). Biochem. J. 66, 490.

Kellie, A. E. \& Wade, A. P. (1957). Biochem. J. 66, 196.

Landau, R. L., Knowlton, K., Lugibihl, K. \& Munson, P. L. (1951). Endrocrinology, 48, 506.

Lieberman, S. (1956). Adrenal Function in Infants and Children, p. 62. Ed. by Gardner, L. I. London: Grune and Stratton.

Lieberman, S. \& Dobriner, K. (1948). Recent Progr. Hormone Res. 3, 71.

Mason, H. L. \& Kepler, E. J. (1945). J. biol. Chem. 161, 235.

Migeon, C. J. (1955). Ciba Foundation Colloq. Endocrin. 8, 141.

Munson, P. L., Jones, M. E., McCall, P. J. \& Gallagher, T. F. (1948). J. biol. Chem. 176, 73.

Plantin, L. O., Diczfalusy, E. \& Birke, G. (1957). Nature, Lond., 179, 421.

Prunty, F. T. G. (1953). J. Endocrin. 9, 244.

Ronzoni, E. (1952). J. clin. Endocrin. Metab. 12, 527.

Roy, A. B. (1956). Biochem. J. 62, 41.

Salter, W. T., Cahen, R. L. \& Sappington, T. S. (1946). J. clin. Endocrin. Metab. 6, 52.

Schiller, S., Miller, A. M., Dorfman, R. I., Sevringhaus, E. L. \& McCullagh, E. P. (1945). Endrocrinology, 37, 322.

Snedecor, G. W. (1952). Biometrics, 8, 85.

Talbot, N. B., Butler, A. M., MacLachlan, E. A. \& Jones, R. N. (1940). J. biol. Chem. 136, 365.

Talbot, N. B., Ryan, J. \& Wolfe, J. K. (1943). J.biol. Chem. 148, 593.

Teich, S., Rogers, J., Lieberman, S., Engel, L. L. \& Davis, J. W. (1953). J. Amer. chem. Soc. 75, 2523.

\title{
Diet and the Action of Cortisone on Protein Metabolism
}

\author{
By G. A. J. GOODLAD* AND H. N. MUNRO \\ Department of Biochemistry, University of Glasgow
}

(Received 11 December 1958)

The general action of administered cortisone is to cause a loss of protein from the body. Some organs, however, do not share in this catabolic

* Beit Memorial Research Fellow. Present address: Department of Biochemistry, Bute Medical Buildings, The University, St Andrews. effect. In the liver and other viscera, there is an accumulation of protein in response to cortisone administration (see review by Trémolières, Derache \& Lowy, 1955). In the experiments to be described below, the influence of diet on these actions of cortisone has been examined. Diets 